\title{
REFLEXÕES SOBRE O CONCEITO KANTIANO DE ESCLARECIMENTO A PARTIR DA TEORIA MARXIANA
}

\author{
Luís Fernando Jacques ${ }^{1}$ \\ Universidade Estadual do Oeste do Paraná (UNIOESTE) \\ https://orcid.org/0000-0002-4332-8212 \\ E-mail: luisjacques90@gmail.com \\ Luana Aparecida de Oliveira ${ }^{2}$ \\ Universidade Estadual do Oeste do Paraná (UNIOESTE) \\ https://orcid.org/0000-0002-9450-8803 \\ E-mail: luanatuba@hotmail.com
}

\begin{abstract}
RESUMO:
A discussão sobre o conceito de esclarecimento perpassa a concepção de Immanuel Kant, que o tematizou enquanto saída do indivíduo da sua condição de menoridade intelectual e de tutela daqueles que impedem o exercício do pensar por si próprio, impelindo a conquista da autonomia que exige a condição de liberdade e de fazer o uso público da razão. Tal problematização acerca das dificuldades interpostas ao processo de esclarecimento pode ser relacionada com o problema do estranhamento em Marx, realizando as devidas ponderações em relação ao contexto histórico e social de ambos os filósofos. Deste modo, por meio da investigação filosófica, é possível estabelecer correlações de complementariedades, diferenças e contrapontos entre as concepções distintas de Kant e Marx. Assim, percebemos que a busca pelo esclarecimento depende da superação das determinações materiais do conjunto de alienações produzidos pelo modo de produção capitalista, visando a conquista da emancipação humana compreendida como liberdade autônoma efetiva.
\end{abstract}

PALAVRAS-CHAVE: Esclarecimento; Estranhamento; Menoridade; Liberdade.

\section{REFLECTIONS ON THE KANTIAN CONCEPT OF ENLIGHTENMENT FROM MARXIAN THEORY}

\begin{abstract}
:
The discussion about the concept of enlightenment runs through the conception of Immanuel Kant, who thematized it as an exit from the individual from his condition of intellectual minority and guardianship of those who prevent the exercise of thinking for himself, impelling the achievement of autonomy that requires freedom and to make public use of reason. Such problematization about the difficulties interposed to the process of enlightenment can be related to the problem of estrangement in Marx, making the necessary considerations in relation to the historical and social context of both philosophers. In this way, through philosophical investigation, it is possible to establish correlations of complementarities, differences and counterpoints between the different conceptions of Kant and Marx. Thus, we realize that the search for enlightenment depends on overcoming the material determinations of the set of alienations produced by the capitalist mode of production, aiming at the achievement of human emancipation understood as effective autonomous freedom.
\end{abstract}

KEYWORDS: Enlightenment; Alienation; Minority; Freedom.

1 Doutorando(a) em Filosofia na Universidade Estadual do Oeste do Paraná (UNIOESTE), Toledo - PR, Brasil.
${ }^{2}$ Doutorando(a) em Filosofia na Universidade Estadual do Oeste do Paraná (UNIOESTE), Toledo - PR, Brasil.

JACQUES, Luís Fernando.; OLIVEIRA, Luana Aparecida de. Reflexões sobre o conceito kantiano de esclarecimento a partir da teoria marxiana. Griot: Revista de Filosofia, Amargosa-BA, v.21 n.3, p.50-60, outubro, 2021. 


\section{Questões introdutórias e contexto histórico}

O esclarecimento foi um conceito discutido por inúmeros filósofos no transcorrer da Idade Moderna e contemporânea. No trabalho a seguir, faremos alguns apontamentos sobre as contribuições que o filósofo Immanuel Kant (1724-1804) propôs ao discutir questões relacionadas ao esclarecimento, mostrando, ainda, as possíveis relações de complementariedade e os contrapontos existentes com o pensamento de Karl Marx (1818-1883).

Antes de mais nada, é necessário entendermos os diferentes contextos históricos a partir dos quais os autores elaboraram suas concepções teóricas. Enquanto, para Kant, a discussão sobre a questão do esclarecimento surge a partir do contexto social e político do Iluminismo, onde a figura do indivíduo é o centro gravitacional de problematização de sua época; Marx desenvolveu sua teoria tendo o conceito de classe social como centro de sua análise filosófica, a partir da qual buscou resolver problemas concernentes ao seu tempo histórico. O que nos interessa aqui é mostrar em que medida as diferentes concepções teóricas dos dois filósofos podem ser complementares e apontarmos possíveis contrapontos a serem observados a partir das suas diferenças de origem ou matriz intelectual.

\section{A problemática do conceito de esclarecimento em Kant}

O filósofo alemão Immanuel Kant viveu no período denominado Iluminismo, cujo pensamento, portanto, reflete a influência desse momento histórico da Europa do século XVIII. Em meio a um debate sobre o conceito de esclarecimento que teve início em 1783 no jornal Mensário Berlinense, publica no ano seguinte Resposta à Pergunta: que é Esclarecimento? [Aufklärung] (1974). Já no primeiro parágrafo de seu artigo, Kant define que: "Esclarecimento [Aufklärung] é a saída do homem de sua menoridade, da qual ele próprio é culpado" (KANT, 1974, p. 100). Em seguida, conceitua menoridade enquanto a incapacidade de fazer uso do próprio entendimento, isto é, de pensar por si mesmo sem ser guiado por outro indivíduo.

Kant aponta que a causa pela qual o indivíduo é culpado pela menoridade a que está submetido reside na covardia e na preguiça de fazer uso próprio de seu entendimento. Conforme o autor, a maioria dos homens e a totalidade das mulheres creem ser difícil e perigosa a saída da menoridade para a maioridade, preferindo delegar a tutores a responsabilidade das tarefas que exigem o pensar por si mesmo. É importante destacar que na filosofia kantiana há um requisito fundamental para o indivíduo fazer uso integral da capacidade de racionar: a liberdade. Assim, o indivíduo somente seria culpado por estar na condição de menoridade na medida em que ele tivesse liberdade para escolher de forma livre sobre se colocar sob tutoria de outro:

Para este esclarecimento [Aufklärung] porém nada mais se exige senão liberdade. E a mais inofensiva entre tudo aquilo que se possa chamar liberdade, a saber: a de fazer um uso público de sua razão em todas as questões (KANT, 1974, p. 104).

Neste ponto, Kant introduz na discussão sobre o esclarecimento a problemática do uso público da razão, a qual possui liberdade ilimitada. Porém, tal exercício de tornar público o pensar por si mesmo de forma racional, somente é possível àqueles que estão inseridos no mundo letrado, os instruídos, isto é, os indivíduos que têm a competência da leitura e da escrita são os que estão aptos para expressar publicamente o que pensam acerca, por exemplo, dos impostos que lhe são cobrados. Em outras palavras, Kant afirma que é preciso ter desenvolvida a habilidade de ler e

JACQUES, Luís Fernando.; OLIVEIRA, Luana Aparecida de. Reflexões sobre o conceito kantiano de esclarecimento a partir da teoria marxiana. Griot : Revista de Filosofia, Amargosa - BA, v.21 n.3, p.50-60, outubro, 2021. 
escrever para possuir condições de argumentar em um debate público sobre o que se defende, tendo em vista que o erudito fará uso público da razão para indivíduos igualmente letrados.

Há também outro sentido de liberdade enquanto requisito ao esclarecimento: trata-se do uso privado da razão. Aqueles que ocupam cargos públicos ou uma atividade que lhes foi confiada são os que fazem o uso privado da razão. Quando se exerce uma determinada função é preciso seguir as regras já estabelecidas, por isso no uso privado da razão a liberdade é restrita, há uma contenção e, portanto, ao invés de se falar em seu próprio nome, o indivíduo tem o dever de obedecer a ordem instituída. Todavia, a liberdade limitada, própria do uso privado da razão, não é considerada prejudicial ao esclarecimento, haja vista que quando o indivíduo não está exercendo o cargo a ele confiado, e enquanto membro de uma comunidade, tem direito de plena liberdade para usar publicamente sua razão. Nas palavras de Kant:

Na medida, porém, em que esta parte da máquina se considera ao mesmo tempo membro
de uma comunidade total, chegando até a sociedade constituída pelos cidadãos de todo o
mundo, portanto na qualidade de sábio que se dirige a um público, por meio de obras
escritas de acordo com seu próprio entendimento, pode certamente raciocinar, sem que
por isso sofram os negócios a que ele está sujeito em parte como membro passivo (KANT,
1974, p. 106).

Dito de outro modo, a diferenciação entre o uso público e o uso privado da razão reside em que no primeiro caso o indivíduo realiza o exercício livre da razão de forma ilimitada, já o segundo se refere ao uso da razão para falar em conformidade com a instituição com a qual está comprometido, sendo que há exigência de um comportamento passivo diante das regras instituídas. Por fim, o artigo de Kant apresenta outro ponto relevante acerca do esclarecimento, lançando a pergunta: “[...] vivemos agora em uma época esclarecida [aufgeklärten]?” (KANT, 1974, p. 112). Embora o século era o das luzes, a resposta do filósofo foi sensata ao diferenciar entre o movimento que deu início à defesa pelo conhecimento racional, e o estado real em que os indivíduos se encontravam. Por isso, Kant questiona se realmente estava em uma época esclarecida, e a resposta é: "[...] não, vivemos em uma época de esclarecimento [Aufklärung]" (KANT, 1974, p. 112). Kant não atribuiu aos indivíduos o adjetivo em questão, pois considerava que, de forma geral, os mesmos até então não possuíam condições de pensar e agir por conta própria, isto é, ainda se encontravam no estado de menoridade. Contudo:

Kant reafirmava suas premissas inicias, ou seja, que em 1784 era possível se vislumbrar a saída progressiva do homem de uma minoridade culpável, ainda que a efetivação dessa realidade estivesse resguardada no futuro (PINHEIRO, 2011, p. 8).

Portanto, na concepção kantiana os indivíduos situados em torno do período de 1780 não eram esclarecidos, mas estavam em processo de esclarecimento, sendo este inevitável desde que houvesse liberdade, quesito indispensável à tarefa de fazer uso do próprio entendimento, isto é, para sair da menoridade. Com isso, podemos compreender que:

Para Kant, o esclarecimento não poderia se dar por meio de uma revolução, mas apenas, por uma reforma lenta no modo de pensar, existente em um ambiente de liberdade (PINHEIRO, 2011, p. 4).

Deste modo, Kant coloca no centro da discussão dos principais problemas que tangem a época do Iluminismo a questão do esclarecimento e a busca da saída da menoridade, conclamando

JACQUES, Luís Fernando.; OLIVEIRA, Luana Aparecida de. Reflexões sobre o conceito kantiano de esclarecimento a partir da teoria marxiana. Griot : Revista de Filosofia, Amargosa - BA, v.21 n.3, p.50-60, outubro, 2021. 
os indivíduos por meio da provocação de uma ousadia do pensar. Portanto, sair da condição de tutela do pensamento exige do indivíduo a vontade do esclarecer-se, de fazer o uso público da razão para romper com as amarras da ignorância e do obscurantismo que não só rondaram o exercício do pensar de sua época, mas que percorrem os diferentes tempos históricos e que transpassam a contemporaneidade de nosso tempo.

Neste sentido, a resposta de Kant transcende seu período histórico, pois não se encerra no esforço de romper com a tutela do pensar apenas de sua época, também nos provoca para que nos mantenhamos alertas em todos os momentos, de modo a não permitir que vontades alheias as nossas nos coloque na condição de menoridade. Para tanto, é preciso ter a ousadia do pensar por si próprio, ainda que isto se torne uma ameaça à ordem social instituída.

\section{A relação entre o conceito de esclarecimento em Kant e o problema do estranhamento em Marx: complementariedades, diferenças e contrapontos}

É por meio da discussão do conceito de esclarecimento em Kant que podemos estabelecer algumas relações com o problema do estranhamento em Marx, cuja reflexão é possível encontrar complementariedades, diferenças e contrapontos entre os dois pensadores. Se para Kant a centralidade da problematização parte do indivíduo, em Marx observamos que é na classe social que a centralidade do debate se apresenta, diferença tal que é compreendida a partir da distinção entre os contextos históricos e intelectuais nos quais os autores estavam inseridos; constituindo assim, suas diferentes concepções teóricas.

Embora Marx não tenha tematizado a questão do indivíduo, isto não significa que o tenha desconsiderado em sua discussão. De certa forma, o indivíduo em Marx encontra-se diluído e incorporado criticamente na classe social, que é onde se apresentam as principais contradições que regem os antagonismos sociais de todas as épocas, formando um fio condutor que permeia e atravessa todas as obras de Marx.

A partir de Marx, considerando que os indivíduos estão inseridos em um contexto histórico e social, é possível fazermos a leitura acerca da menoridade a que eles estão submetidos enquanto uma forma de estranhamento. Porém, o conceito de estranhamento, inserido na teoria marxiana, difere substancialmente do conceito kantiano de menoridade. $O$ estranhamento pode ser entendido como um complexo de fenômenos sociais, sendo que Marx a distingue em quatro aspectos diferentes: $1^{\circ}$ : estranhamento do trabalhador em relação ao produto de seu trabalho; $2^{\circ}$ : estranhamento do trabalhador com a própria atividade de trabalho; $3^{\circ}$ : estranhamento do trabalhador em relação a si mesmo; e $4^{\circ}$ : estranhamento do trabalhador em relação ao conjunto da classe trabalhadora (MARX, 2004).

Embora o estranhamento seja imanente ao modo de produção capitalista, ele não se dá a partir do sistema capitalista, pois anteriormente a este, já havia complexos de estranhamentos, até mesmo formas menos desenvolvidas de estranhamento, ou seja, formas rudimentares. Conforme Marx, sua gênese está na propriedade privada, sendo a terra o primeiro bem natural transformado em propriedade privada.

[...] a propriedade fundiária é a primeira forma de propriedade privada, assim como a indústria historicamente se lhe defronta antes de tudo simplesmente como uma espécie particular de propriedade - ou melhor, é o escravo liberto da propriedade fundiária (MARX, 2004, p. 102).

Em relação à propriedade privada, Marx destaca seu caráter alienante:

JACQUES, Luís Fernando.; OLIVEIRA, Luana Aparecida de. Reflexões sobre o conceito kantiano de esclarecimento a partir da teoria marxiana. Griot : Revista de Filosofia, Amargosa - BA, v.21 n.3, p.50-60, outubro, 2021. 
A propriedade privada nos fez tão cretinos e unilaterais que um objeto somente é o nosso [objeto] se o temos, portanto, quando existe para nós como capital ou é por nós é imediatamente possuído, comido, bebido, trazido em nosso corpo, habitando, por nós etc., enfim, usado (MARX, 2004, p. 108).

No modo de produção capitalista, desde que o trabalhador queira suprir suas necessidades do estômago ou do espírito e suprir também as necessidades de sua família, terá sua força de trabalho condicionada às determinações daquele que a comprou, conforme a lógica capitalista estabelecida. Neste sentido, a força de trabalho se torna uma mercadoria, sendo esta a essência do estranhamento na sociedade na qual predomina o capital:

O trabalhador se torna tanto mais pobre quanto mais riqueza produz, quanto mais a sua produção aumenta em poder e extensão. $\mathrm{O}$ trabalhador se torna uma mercadoria tão mais barata quanto mais mercadoria cria. Com a valorização do mundo das coisas aumenta em proporção direta a desvalorização do mundo dos homens. $O$ trabalho não produz somente mercadorias; ele produz-se a si mesmo e ao trabalhador como uma mercadoria, e isto na medida em que produz, de fato, mercadorias em geral (MARX, 2004, p. 80).

Por meio da análise marxiana, entendemos que o trabalho é considerado a atividade fundante do ser humano, ou seja, a categoria que funda o ser social. Ou seja, o trabalho é a atividade vital, genérica, que atravessa todo o processo de constituição geral dos homens, assim como a formação individual que participará do tecido social. Porém, na sociedade capitalista a força de trabalho é convertida sob a forma mercadoria, logo, em trabalho estranhado.

É sabido que em Marx o ser humano é o único ser capaz de transformar a natureza por meio de uma ação previamente orientada, isto é, uma ação consciente que objetiva realizar um projeto, o qual foi idealizado de forma prévia tendo em vista satisfazer uma necessidade concreta. Portanto, o trabalho é essa atividade que transforma a natureza de modo a objetivar uma prévia ideação. Assim, conforme a teoria marxiana, os animais não trabalham no sentido scricto do conceito, pois não possuem tal capacidade:

Pressupomos o trabalho numa forma em que pertence exclusivamente ao homem. Uma
aranha executa operações semelhantes às do tecelão, e a abelha envergonha mais de um
arquiteto humano com a construção dos favos de suas colmeias. Mas o que distingue, de
antemão, o pior arquiteto da melhor abelha é que ele construiu o favo em sua cabeça,
antes de construí-lo em cera. No fim do processo de trabalho obtém-se um resultado que
já no início deste existiu na imaginação do trabalhador, e portanto idealmente (MARX,
1996, p. 297-298).

A atividade que, por exemplo, as abelhas e as aranhas desenvolvem, é determinada geneticamente, pois antes destes animais construírem uma teia ou um favo de mel eles não projetam na consciência a ação e o resultado da ação. Em síntese, conforme já vimos, a atividade que é própria do ser humano, a saber, o trabalho, é transformado em trabalho estranhado devido à força de trabalho que o modo de produção capitalista reduz à mercadoria. Assim, na mesma medida que os sujeitos são objetificados, os objetos são subjetivados:

A essência da alienação da sociedade capitalista é que ela trata como mercadoria o que é humano; e, como mercadoria é coisa e não gente, a desumanidade desse tratamento não poderia ser maior (LESSA, 2008, p. 100).

JACQUES, Luís Fernando.; OLIVEIRA, Luana Aparecida de. Reflexões sobre o conceito kantiano de esclarecimento a partir da teoria marxiana. Griot : Revista de Filosofia, Amargosa - BA, v.21 n.3, p.50-60, outubro, 2021. 
Após discorrermos sobre o conceito marxiano de estranhamento, convém fazermos os apontamentos e correlações com o conceito de menoridade atribuído por Kant. Para tanto, partiremos do idealismo kantiano. Este compreende que as ideias e a consciência possuem papel decisivo na história. Embora Kant não negue a existência da matéria, em última instância a primazia é da consciência, pois é ela que reconhece a relação do ser humano com o mundo material, relação objetiva expressa em leis fundamentadas " [...] a priori por nossas formas de intuição e de pensamento" (SCHMIED-KOWARZIK, 2019, p. 26).

Segundo Lessa e Tonet, Marx, entretanto, inverte o pressuposto do idealismo kantiano: "Sem a materialidade natural não poderia existir a consciência dos homens. Nesse preciso sentido, a matéria é anterior à consciência" (LESSA, 2008, p. 43). Conforme esses autores, o materialismo histórico dialético, método científico proposto por Marx, busca superar o idealismo alemão, visto que "Ele possibilita compreender a base material das ideias, e ao mesmo tempo, a força material das ideias na reprodução social" (LESSA, 2008, p. 45).

A partir do materialismo histórico dialético, podemos entender que são as condições objetivas da existência que determinam a consciência: "Não é a consciência que determina a vida, mas a vida que determina a consciência" (MARX, 1999, p. 37). Dessa forma, a história é feita pelo próprio ser humano. Embora não é possível escolher as condições com as quais a fazem. "Os homens - e apenas eles - são responsáveis por suas misérias. Foram os homens que construíram as alienações geradas pelo predomínio do capital na vida social; cabe a eles superarem tais alienações" (LESSA, 2008, p. 96).

Assim sendo, é preciso compreendermos que ao afirmar que "os homens são responsáveis por suas misérias", não significa culpabilizar de forma individual cada sujeito, mas buscar entendê-los na universalidade enquanto gênero humano e artífice de sua própria história, circunscrita ao seu tempo. Se "foram os homens que construíram as alienações" ao longo de um processo histórico e social, então elas não são eternas e imutáveis, haja vista que os homens podem superá-las. Entretanto, por meio da análise marxiana entendemos ser necessário ressaltar que a consciência de uma determinada época refletirá as ideais da classe dominante dessa época, sendo que a classe que domina materialmente, também domina espiritualmente:

As idéias (Gedanken) da classe dominante são, em cada época, as ideias dominantes; isto é, a classe que é a força material dominante da sociedade é, ao mesmo tempo, sua força espiritual dominante (MARX, 1999, p. 72).

Desse modo, considerando a ideologia que domina determinada época e levando em conta as mediações contextuais e históricas necessárias, o conceito kantiano de menoridade pode ser entendido a partir de uma concepção marxiana enquanto estranhamento a que o sujeito está submetido, a qual na sociedade do modo de produção capitalista ocorre nas mais diversas formas, nas mais simples até as mais complexas.

Preguiça, covardia e comodidade são atribuições que não são suficientes para compreender a totalidade de fenômenos sociais que permeiam os sujeitos inseridos na sociedade, além de encobrir na esfera da individualidade subjetiva o conjunto dos diversos complexos de estranhamentos na qual os indivíduos estão acometidos. Para tal análise, é necessário não somente observar o sujeito enquanto indivíduo, mas sim a totalidade do contexto histórico e a dimensão social, ou seja, é necessário levar em consideração a classe social da qual ele faz parte.

Outro aspecto relevante para ser refletido é acerca da liberdade, pois na medida em que o indivíduo é livre, ele é responsável por estar e permanecer na menoridade. Todavia, podemos questionar até que ponto o indivíduo realmente é livre, ao passo que o Capital possui liberdade garantida para

JACQUES, Luís Fernando.; OLIVEIRA, Luana Aparecida de. Reflexões sobre o conceito kantiano de esclarecimento a partir da teoria marxiana. Griot : Revista de Filosofia, Amargosa - BA, v.21 n.3, p.50-60, outubro, 2021. 
explorar o trabalhador, se apropriando do produto resultante do tempo de trabalho não remunerado, a mais-valia. Neste sentido nos perguntamos, liberdade para quem? "[...] Liberdade do capital para explorar os trabalhadores" (LESSA, 2008, p. 89).

Assim sendo, na sociedade das trocas regida pelo mercado, quem possui o requisito para o esclarecimento, a liberdade incondicionada, são os proprietários de bens, de propriedade privada e de meios de produção. Os trabalhadores são os não-proprietários, os despossuídos, aqueles que têm sua liberdade condicionada, restrita; cuja liberdade limitada se restringe a alienar, vender a única propriedade da qual são possuidores: a sua própria força de trabalho. Assim, para garantir a sua subsistência material e de sua família, necessita aliená-la, submetê-la à autoridade econômica dos proprietários de meios de produção.

Kant, no entanto, permeado pelas circunstâncias históricas e sociais de seu tempo, tomou o conceito de liberdade enquanto princípio metafísico, abstrato, idealizado, não conseguindo chegar a percebê-lo nas suas mediações materiais; cujas circunstâncias políticas e sociais logo depois de algumas décadas iriam se alterar substancialmente com as fases de desenvolvimento da Revolução Industrial e as profundas transformações no mundo do trabalho.

Contudo, o que pretendemos apontar aqui é a necessidade de pensarmos as condições materiais e efetivas para o exercício da liberdade levando em consideração a esfera social do mundo do trabalho e os complexos de estranhamentos. Ao tratar os sujeitos como indivíduos abstraídos do seu contexto social material, Kant não conseguiu dar a devida atenção à dimensão histórica dos mesmos. Então, podemos fazer outro questionamento: será que o indivíduo prefere ser tutelado, no sentido de ser uma escolha consciente a delegação de sua tutoria a outro, ou é porque encontra-se imerso a uma ideologia que oculta a realidade e lhe incute uma falsa consciência sobre um conjunto de valores que não são os seus, e sim da classe dominante?

Podemos afirmar que a filosofia de Kant, que buscou encontrar um fundamento racional e universal que fosse válido em todas as épocas e para todos os seres racionais, acabou por não atingir o nível de uma reflexão mais criteriosa no sentido social concreto, em relação à história e a tudo que ela representa ao desenvolvimento material da humanidade; assim como as condições concretas para o uso dessa liberdade enquanto requisito para a saída da menoridade e o alcance pleno do esclarecimento.

Essa lacuna teórica é de certo modo reflexo da promessa de Kant em elaborar um estudo sobre a antropologia que não o fez. Isso significa que ser livre, ousando pensar por si mesmo, implica em considerar a busca por mediações sociais, além de condições materiais e objetivas para o exercício dessa liberdade, sobretudo econômica, no sentido que existe uma parte considerável da humanidade que não possui os meios de subsistência, o qual coincide com a parcela de indivíduos na condição de menoridade.

Não há como negar, a partir de uma concepção marxiana, a necessidade de requisitos objetivos da vida material para sair da condição de tutelado, um esforço para compreender as mediações que vão para além da ousadia da vontade e do querer, na qual se enraízam no substrato material do mundo social e do trabalho: "A produção de ideias, de representações, da consciência, está, de início, diretamente entrelaçada com a atividade material e com o intercâmbio material dos homens, com a linguagem da vida real" (MARX, 1999, p. 36).

Kant circunscrito ao espírito de seu tempo, todavia, não percebeu o poder de influência que as ideias da classe dominante exercem sobre o conjunto dos trabalhadores, com isso, não vislumbrou este aspecto na relação com a dificuldade de ousar pensar por si mesmo, cuja dificuldade se dá justamente em decorrência da ideologia dominante. Já em Marx, dadas as devidas ponderações, sair da condição de tutela, isto é, do estranhamento, representa, de modo

JACQUES, Luís Fernando.; OLIVEIRA, Luana Aparecida de. Reflexões sobre o conceito kantiano de esclarecimento a partir da teoria marxiana. Griot : Revista de Filosofia, Amargosa - BA, v.21 n.3, p.50-60, outubro, 2021. 
geral, o momento em que os trabalhadores pensarão ideias que não sejam as pertencentes da classe dominante.

Dessa forma, seriam os próprios tutores, sendo que em termos marxianos diríamos a classe dominante, os responsáveis por fazer com que os indivíduos permaneçam na menoridade. Kant, aparentemente apresenta algumas contradições e diferenças em algumas passagens, pois em alguns momentos realiza uma análise sobre os fatores de culpa que condicionam o indivíduo pelo seu estado de menoridade, tendo como pressuposto a liberdade, ainda que seja uma liberdade limitada, e noutro contexto, assevera sobre os tutores que se encarregam de "bom grado" dessa função, e que tomam para si a direção de seus tutelados:

Depois de terem primeiramente embrutecido seu gado doméstico e preservado cuidadosamente estas tranqüilas criaturas a fim de não ousarem dar um passo fora do carrinho para aprender a andar, no qual as encerraram, mostram-lhes, em seguida, o perigo que as ameaça se tentarem andar sozinhas. Ora, este perigo na verdade não é tão grande, pois aprenderiam muito bem a andar finalmente, depois de algumas quedas. Basta um exemplo deste tipo para tornar tímido o indivíduo e atemorizá-lo em geral para não fazer outras tentativas no futuro (KANT, 1974, p. 102).

Em outras palavras, os tutores exercem controle sobre os indivíduos para que eles permaneçam no estado de menoridade, ou em termos marxianos, no estranhamento que interfere os sujeitos a exercerem a própria liberdade em sua dimensão plena. Todavia, esta liberdade é negada ao indivíduo, seja no processo de constituição da sociedade capitalista, seja porque impossibilitada diante das determinações coisificadas produzidas na estrutura desta sociedade. $\mathrm{O}$ principal exemplo, conforme já abordamos, é o trabalho estranhado que não permite a efetiva liberdade, tendo em vista que ele é antagônico à liberdade, ao passo que o trabalhador é apenas um produtor de mercadorias, e na mesma proporção sua força de trabalho também se torna uma mera mercadoria:

[...] sob relações capitalistas, o homem objetiva sua existência através do trabalho e não mais retorna sobre si; a alienação em relação ao produto do seu trabalho, à atividade produtiva, a si próprio como ser genérico e aos outros homens como relação social impede que a liberdade seja alcançada na esfera objetiva da produção econômica (OLIVEIRA, 1998, p. 189).

Marx desvela a verdade velada, a saber, no mundo capitalista não há espaço para a liberdade, pois na base concreta das relações materiais está, em síntese, a exploração do homem pelo homem. O que não permite condições objetivas de possibilidade para a efetivação da liberdade. A liberdade é anulada na sociedade em que as necessidades do Capital, os interesses privados dos donos dos meios de produção, predominam sobre as necessidades humanas. Para Marx, considerando os processos estranhados do modo de produção capitalista, a liberdade de fato somente se efetivaria a partir do momento em que a classe dominada, dos explorados, se libertasse da subjugação da classe dominante, dos exploradores; ou seja, com a superação da sociedade capitalista. Nas palavras de Lessa e Tonet:

O "reino da liberdade" só pode vir com a superação do capital e da sociedade burguesa. Só por essa via será possível colocar em primeiro lugar o que é primordial: as necessidades humanas. Ao libertá-las do jugo do capital, tornar-se-á evidente o absurdo de se promover a miséria dos trabalhadores para se conseguir a estabilidade e o desenvolvimento econômico; tornar-se-á patente a barbaridade que significa produzir desemprego, fome e

JACQUES, Luís Fernando.; OLIVEIRA, Luana Aparecida de. Reflexões sobre o conceito kantiano de esclarecimento a partir da teoria marxiana. Griot : Revista de Filosofia, Amargosa - BA, v.21 n.3, p.50-60, outubro, 2021. 
marginalização social para que o desenvolvimento das forças produtivas possa continuar. O "reino da liberdade", segundo Marx, nada mais é do que o atendimento das verdadeiras e reais necessidades humanas, postas pelo desenvolvimento histórico e social (LESSA, 2008, p. 124).

Em última análise, a revolução, enquanto um processo social e político, é condição para a liberdade real. Todavia, para Kant, conforme já abordamos, a revolução não está na ordem do dia quando se trata da saída da menoridade: "Uma revolução poderá talvez realizar a queda do despotismo pessoal ou da opressão ávida de lucros ou de domínios, porém nunca produzirá a verdadeira reforma do modo de pensar" (KANT, 1974, p. 104). Por outro lado, Kant admite a dificuldade do indivíduo sair sozinho da condição de menoridade, ao passo que, não raras vezes, cria-se um sentimento pelo estado que se encontra, de modo que se torna impossível fazer uso da própria capacidade racional e pensar por si mesmo. Como escreve Kant:

É difícil portanto para um homem em particular desvencilhar-se da menoridade que para ele se tornou quase uma natureza. Chegou mesmo a criar amor a ela, sendo por ora realmente incapaz de utilizar seu próprio entendimento, porque nunca o deixaram fazer a tentativa de assim proceder (KANT, 1974, p. 102).

Podemos compreender, a partir de uma leitura marxiana que faz a crítica à sociedade capitalista, que, de modo geral, trata-se da ideologia dominante quando se fala: "[...] nunca o deixaram fazer a tentativa de assim proceder" (KANT, 1974, p. 102). Sobre a teoria kantiana é possível questionar: o quê ou quem não deixa o indivíduo utilizar seu próprio pensar? Quais são os tutores? A título de exemplificação, o filósofo menciona que pode ser um livro, um diretor espiritual, um médico, ou quaisquer outros, desde que o indivíduo não queira se encarregar de pensar e gerenciar os assuntos desagradáveis, pagando, assim, alguém que se encarregue de tais atividades.

Novamente, percebemos aspectos distintos na reflexão de Kant, na qual afirma que há tutores que não permitem o indivíduo pensar por si mesmo: “[...] nunca o deixaram fazer a tentativa de assim proceder" (KANT, 1974, p. 102). Mas, ao mesmo tempo, atribui à escolha dos próprios indivíduos a condição de estarem sob tutela: "Não tenho necessidade de pensar, quando posso simplesmente pagar; outros se encarregarão em meu lugar dos negócios desagradáveis" (KANT, 1974, p. 102).

Se, por um lado, há escolha de ser tutelado, sendo o guia espiritual, o médico e o livro exemplos de tutores escolhidos: "Se tenho um livro que faz as vezes de meu entendimento, um diretor espiritual que por mim tem consciência, um médico que por mim decide a respeito de minha dieta, etc., então não preciso esforçar-me eu mesmo" (KANT, 1974, p. 102). Então, por outro lado, a pergunta continua sendo: quem ou o quê em Kant representa os tutores que não deixam que o indivíduo pense por conta própria, para além daqueles que escolhem ser tutelados?

Podemos concluir que Kant realizou uma grande contribuição ao desenvolver a relação entre os conceitos de liberdade e autonomia e suas significações no âmbito teórico-conceitual. A partir de Kant, elevamos o nível de compreensão sobre a liberdade como um atributo intrínseco da vontade de seres racionais, na qual exterioriza suas determinações objetivas por meio do conceito de autonomia, condições sine qua non para a saída do ser humano da condição de menoridade e tutela intelectual.

Contudo, falta em Kant a compreensão da dimensão das determinações materiais e condições sociais necessárias para a conquista da autonomia, a isto atribuímos as circunstâncias históricas e o espírito de sua época. Em Marx, todavia, encontraremos uma profunda análise sobre

JACQUES, Luís Fernando.; OLIVEIRA, Luana Aparecida de. Reflexões sobre o conceito kantiano de esclarecimento a partir da teoria marxiana. Griot: Revista de Filosofia, Amargosa-BA, v.21 n.3, p.50-60, outubro, 2021. 
a situação material e socioeconômica em que os seres humanos se encontram na sociedade moderna e contemporânea; tal análise contribui para superar a condição posta por Kant como menoridade. Condição que coincide com aquilo que os sujeitos na situação de tutela são,

[...] portanto, com sua produção, tanto com o que produzem, como com o modo como produzem. $\mathrm{O}$ que os indivíduos são, portanto, depende das condições materiais de sua produção (MARX, 1999, p. 27-28).

Assim sendo, a partir desta reflexão, compreendemos que os sentidos do esclarecimento que visam a conquista de uma liberdade autônoma, não subordinada ao capital, dependem da superação das determinações materiais do complexo de estranhamentos produzidos pelo modo de produção capitalista; os quais impossibilitam os sujeitos de realizarem a jornada rumo à emancipação humana: por isso a urgência da superação de tal modo de produção.

JACQUES, Luís Fernando.; OLIVEIRA, Luana Aparecida de. Reflexões sobre o conceito kantiano de esclarecimento a partir da teoria marxiana. Griot : Revista de Filosofia, Amargosa - BA, v.21 n.3, p.50-60, outubro, 2021. 


\section{Referências}

KANT, Immanuel. Resposta à Pergunta: que é Esclarecimento? [Aufklärung]. In: Textos seletos. Tradução: Floriano de Sousa Fernandes. Petrópolis: Vozes, 1974. p. 100-117.

LESSA, Sérgio; TONET, Ivo. Introdução à Filosofia de Marx. São Paulo: Expressão Popular, 2008.

MARX, Karl. O Capital: Crítica da Economia Política. Vol. I. Livro 1 O Processo de Produção do Capital. Tradução: Regis Barbosa, Flávio R. Kothe. São Paulo: Nova Cultural,1996.

MARX, Karl. Manuscritos Econômico-filosóficos. Tradução: Jesus Ranieri. São Paulo: Boitempo, 2004.

MARX, Karl; ENGELS, Friedrich. A Ideologia Alemã. Tradução: José Carlos Bruni, Marco Aurélio Nogueira. São Paulo: HUCITEC, 1999.

OLIVEIRA, Avelino da Rosa. O problema da liberdade no pensamento de Karl Marx. In: Revista Perspectiva: Filosofia e Educação. v. 16, n. 29. Ano 1998. Disponível em: https://periodicos.ufsc.br/index.php/perspectiva/article/viewFile/10638/10171. Acesso em maio de 2019.

PINHEIRO, Rossana Alves Baptista. Luzes e sombras no Iluminismo kantiano. Disponível em: http://www.snh2011.anpuh.org/resources/anais/14/1300876862_ARQUIVO_ANPUH2011.pdf.

Anais do XXVI Simpósio Nacional de História - ANPUH. São Paulo, julho 2011. Acesso em junho de 2019.

SCHMIED-KOWARZIK, Wolfdietrich. A relação dialética do homem com a natureza: estudos históricos-filosóficos sobre o problema da natureza em Karl Marx. Tradução de Rosalvo Schütz, revisado por Hans-Georg Flickinger. Cascavel: Edunioeste, 2019.

Contribuição dos(as) autores(as) / Author's Contributions: Luís Fernando Jacques e Luana Aparecida de Oliveira participaram da pesquisa, discussão e redação do artigo. Ambos aceitaram e aprovaram a versão final do texto.

Autor(a) para correspondência / Corresponding author: Luís Fernando Jacques. luisjacques90@gmail.com

JACQUES, Luís Fernando.; OLIVEIRA, Luana Aparecida de. Reflexões sobre o conceito kantiano de esclarecimento a partir da teoria marxiana. Griot : Revista de Filosofia, Amargosa - BA, v.21 n.3, p.50-60, outubro, 2021. 